\title{
Teacher Hiring: Exploring the Dilemmas and the Solutions
}

\author{
Nancy Maynes and Blaine E. Hatt \\ Nipissing University
}

Received: March 13, 2015 Accepted: March 24, 2015 Published: May 1, 2015

doi:10.5296/jse.v5i2.7233 URL: http://dx.doi.org/10.5296/jse.v5i2.7233

\begin{abstract}
This paper reports on three related pieces of research and academic writing. Initially, mixed methods research was undertaken to ascertain the views of school administrators regarding criteria, which they value in the process of hiring new teachers. One overarching conclusion from this research is that administrators who have responsibility for hiring new teachers are not universally confident in the interview process as a strategy for helping them to identify the best teachers to hire. This research is then framed in the context of two academic books which each has a related premise. The first book is addressed to new teachers to help them understand how to prepare for, manage, and reflect upon a teaching interview. The second book is addressed to school and system administrators to suggest an alternative multi-stage process that could strengthen current hiring practices to help jurisdictions ensure that the best teachers are ultimately hired to teach.
\end{abstract}

Key words: Teacher interviews, Teacher hiring, Preparing for a teaching interview 


\section{Introduction}

During the past three years, research into teacher hiring practices was undertaken in response to new provincial legislation about teacher hiring. In this jurisdiction, newly certified teachers must flow through a three-step gradual hiring sequence in order to acquire a teaching contract position. After submitting a written application, they may be interviewed to acquire a placement on the school board's supply teacher list. Second, they are offered a long-term occasional position. Only after proving themselves in both of these contexts may these new teachers be offered a contract position.

In some areas of this jurisdiction, the opportunity to apply for the supply teachers' list may open up infrequently. This can happen if a school board has a long list of supply teachers and can satisfactorily fill the need for supply teachers from the existing pool of teachers on the list. When the teachers' union and the board agree that the need for supply teachers exceeds the available people in the pool, the supply list is opened and newly graduated teachers can apply to be interviewed. This process is responsive to two conditions in this jurisdiction: 1) there is an overabundance of newly graduated teachers in the area; and 2) it has become increasingly difficult to remove ineffective teachers from the classroom. This gradual pre-contract hiring process protects school boards from poor decisions about hiring.

There is little doubt that the quality of the teachers we are hiring for our schools is a critically important decision. However, it may be that hiring teachers who have the most desirable skills and attitudes for the profession can be problematic. In some jurisdictions, hiring team members may have little background in hiring approaches and may have little to no training for the task of teacher hiring. Additionally, in some instances, interview questions for hiring teachers are being selected or scripted by people other than the actual interviewers. This is problematic because the topics, scope, and focus of questions reflect a set of beliefs about what characteristics are of value in new teachers. These may not be the beliefs that are common to those people actually involved in the hiring, and in some cases, may reflect foci that are not even understood by the hiring teams.

Also problematic is the relatively short time invested in making decisions about whom to hire. A typical teacher-hiring interview is often less than 30 minutes. In this brief span of time, interview teams must try to make the best possible decision about whom to hire. This is a daunting prospect when one considers that the outcome of this 30-minute decision-making process can have a strong impact on many young people in our schools for a timespan of many years.

Equally problematic is the inequity in local legislation that may influence how teachers can be hired and the filtering processes that they may have to engagein before they are even offered an interview. In the Canadian context, inequities are the result of the provincial or territorial jurisdiction over educational mandates. A further inequity exists and complicates the current selection process; namely, teachers' federations or unions are very effective at doing what they were constituted to do. Federations protect teachers. In the hiring process, this can create problems for teacher hiring because federations and/or unions protect the rights of the teachers who are already hired, even if/when a teacher is ineffective. This reality 
may cause hiring teams to be overly cautious about whom they hire for new teaching positions. Few will disagree that hiring new teachers is a high stakes process, yet our research is also showing that many administrators lack confidence in the process that has historically been used in their jurisdiction.

\section{Literature Review}

The research literature about teacher hiring stresses the importance of hiring effectively, to ensure that the teachers with the most potential to have a positive impact on student achievement enter classrooms as contract teachers. A key contributor to the academic success of students is the quality of the classroom teachers with whom they spend their instructional time (OECD, 2004, 2005; Rivkin, Hanushek, \&Kain, 2005). The impact of the teacher is a higher influential factor in determining who may succeed and who may not, than other factors such as school climate (Dinham, Ingvarson, \&Kleinhenz, 2008) or standardized test scores. Our recognition of this influence highlights the crucial nature of effective hiring practices to ensure that new teachers who show the most potential forensuring high levels of student achievement and commitment to high standards of accomplishment, are the people who are selected to teach (Walsh \& Tracy, 2004).

Although school and jurisdiction hiring teams have a vested interest in implementing effective hiring strategies to increase the chances of improving student success (OECD, 2004; 2005), the practices in place in their system may be unsupportive of this goal (Lambeth, 2012). School systems attempt to leverage student success by ensuring that those responsible for hiring new teachers hire quality teachers and then support their continuous growth once they are in the profession (Bieler, 2012; Brock \&Chatlain,2008;Cherubini; 2009; Clark \& Byrnes, 2012; Darling-Hammond, 2001; 2003;Glassford\&Salinitri, 2007; Harris, 2004;) through systems of mentoring, although the effectiveness of the mentoring depends greatly on the quality of the match between the new teacher and mentor (Martin, Andrews, \& Gilbert, 2009; OECD , 2012) and may be influenced by the teacher's own resiliency and relationships established with colleagues (Tait, 2005). In the jurisdiction where this research was completed, on-the-job mentoring takes many forms and it appears that little has been done to determine the short or long-term impact of professional practice on student achievement as a result of any of these approaches. However, other research has shown the potential benefits of early career mentoring. Kelley (2004) concluded that quality induction, with a focus on collaboration and resource sharing, had "lasting effects on teacher quality and retention" ( $p$. 447).Hentges (2012) also found that longer training programs and increased practica experience significantly increased the retention of new teachers, which may provide further guidance for those who hire new teachers and evaluate the credentials they offer.This finding was supported by the work of Ingersoll, Merrill, and May (2012).

Additionally, Teague and Swan (2013) found that teachers hired later in the year did not benefit from the established jurisdictional mentorship and induction programs and desired greater support. This finding may provide jurisdictional direction for how to design early career induction programs and when hiring should ideally take place. 
School and system administrators who are charged with hiring teachers can be assumed to be trying to ensure that they hire the most effective teachers. Generally, interviews and other filtering strategies for hiring have criteria that support the interview selection process. Such criteria may be stated in jurisdictional policy documents or identified in selection criteria and retention supports for newly hired teachers. Sometimes these criteria appearin the form of key phrases that interviewers are to listen for in responses (Young, Levin, \&Wallin, 2007).

However, in some school boards or districts, hiring teams may lack local or jurisdictional policies to guide their selection process. In this case, hiring teams may be guided by personal perceptions, idiosyncratic assessments, and relatively unacknowledged value judgments (Cranston, 2012). To complicate the selection of hiring new teachers, it may be that hiring individuals or hiring teams have different conceptions of teacher effectiveness (Little, Goe, \& Bell, 2009) and little time to establish common conceptions during the processes used in their jurisdiction.

In the absence of time and structure to ensure that hiring administrators share a common vision for those teachers they hire, defining an effective teacher may, in actual hiring practice, be a subjective and interpretive act (Cochran-Smith and Power, 2010; Rabinowicz\& Travers, 1953) resulting in less that optimal hiring decisions. Also, there may be little consensus on the usefulness of a hypothetical or narrow definition of teacher effectiveness (Campbell, Kyriakides, Muijs, \& Robinson, 2003) and those charged with hiring effective teachers may disagree about what effectiveness is in the context of the new position. Without consensus on the goal of hiring teachers, defined by an effective way to measure their potential to have a positive impact on student success, the hiring process may be undermined by weak preparation among those charged with the task of selecting new teachers.

There is no known method of consistently predicting the effectiveness of a teacher in the classroom once they are hired (Cashin, 1994). This reality further complicates the task of a hiring team. There is, however, general agreement among researchers that a teacher's actual classroom performance may have some predictive value about their future successes in the classroom (Bill and Melinda Gates Foundation, 2010; Gladwell, 2008; Goldhaber \& Hansen, 2010; Jacob \& Lefgren, 2006). Based on this premise, jurisdictions may rely heavily on written reports of the teacher's classroom work during their teacher preparation program. Jurisdictions use written reports of prior classroom performance as filters for selecting from the cadre of potential employees those who show the most promise to leverage student achievement by their effectiveness in the classroom (Darling-Hammond \& Berry, 1999; OECD, 2004; 2005: Wise, Darling-Hammond \& Berry, 1987). Aside from written reports about classroom performance, it is not typical for actual classroom demonstrations of an applicant's teaching skill(s) to be included as an aspect of an interview or as part of the usual approaches for hiring.

Many jurisdictions rely heavily on a brief interview to identify the most promising new teachers. And, while many jurisdictions train their hiring personnel to use performance based interviewing techniques to structure questions that bridge the gap between past practice and future practices, some hiring teams receive no training at all. In such instances, practice 
teaching reports may take on a disproportionate importance in the hiring process. Jurisdictions, in an attempt to improve the quality of the interview process and their screening practices may select those applicants who demonstrated the highest success during their student teaching placements.

Fit theory may help organizations such as school boards develop systematic ways of thinking about whom they hire to teach in their classrooms. Fit theory holds that organizations try to hire new personnel potentially based on acknowledged or unacknowledged understandings of how the newly hired person will fit the needs of the organization (Vessey, 2006). Problematic, however, is the inequity of preparation to help hiring administrators understand such concepts prior to facing the task of hiring new teachers. If the interview is the main filter used by jurisdictions to hire new teachers, then it ought to be a system process that is well understood and confidently relied upon to ensure that the best teachers are selected to teach.

The effort to improve screening by improving interview quality is essentially an effort to match the organizational needs with the available talents of applicants and the classroom demands of an effective teacher (Herriot, 1989; Montgomery, 1996; Plumbley, 1985; Zhu \& Dowling, 2002). This effort may help potential employers design and use strategies that help their organization identify the most promising teacher qualities (Cochran-Smith \& Power, 2010). However, this practice is inherently problematic if jurisdictions fail to use a systematic, research-based approach to the hiring practices, and especially problematic if the employer relies heavily upon an ineffective, single method of high-stakes decision-making in selecting new teachers (Boyd, Goldhaber, Lankford, \& Wyckoff, 2007; Walsh \& Tracy, 2004).

Cranston (2012) suggested that the hiring choices of principals could greatly affect a school's culture, and was therefore interested in the process involved in this decision. He interviewed 8 principals within a Manitoba Catholic school board twice over a year to determine the criteria they used and the weight they gave each criterion. Although it was a small sample, he felt the findings were likely representative of a wider population. Cranston (2012) concluded that principals made hiring decisions based on the 'fit' of applicants. He suggested 'fit' was considered in four ways: person-vocation $(\mathrm{P}-\mathrm{V})$, person-job $(\mathrm{P}-\mathrm{J})$, person-organization $(\mathrm{P}-\mathrm{O})$ and person-group (P-G) fit.

Principals determined, typically through interviews and references, if an applicant fit the vocation based on their past choices, interests, and characteristics. P-J fit was generally the foundation of selection, when applicants were screened based on the skills, qualifications, and abilities required of the job. This was usually done based on an applicant's cover letter and resume, and was believed to be a strong factor in job satisfaction, motivation, performance, and retention. P-O and P-G fit, also determined through cover letters and interviews, involved making sure the applicant shared the organization's values and would work well with current members of the team. The applicant's ability to collaborate and work as a team-member was highly valued. Cranston (2012) suggested this aspect of fit could be problematic as applicants are judged at one and the same time on their ability to fit in and their ability to bring about change and innovation. 
In addition, Cranston (2012) found that principals played a key role in determining who entered the teaching profession or taught within the school even though they did not have formal training or preparation in making such decisions. Principals believed it was their responsibility and ability to assess applicants' 'fit' to the profession in general. Cranston (2012) suggested that principals judged applicants' 'fit' against their own values and beliefs on what it meant to be a good educator and determined P-O and P-G fit, using "self-reference standards" (p. 22).

Finally, Cranston (2012) posited that assessment of applicants was highly subjective, especially when using interviews and references, where $\mathrm{P}-\mathrm{O}$ and $\mathrm{P}-\mathrm{G}$ fit played a significant role in applicant selection. More objective criteria, like applicant's credentials and experience, were generally used in initial stages of the process to weed out unqualified applicants. It was evident in this research that in these instances, personal biases dominated the assessment of applicants' fit (p. 21) both within the specific school, and the profession as a whole, resulting in the possibility that many qualified individuals were overlooked.

Current hiring practices may, therefore, be challenged in two key ways. First, evidence that school jurisdictions make effective decisions about whom they hire in the selection of teachers is largely unavailable (Boyd et al, 2007). Recent research (Maynes \& Hatt, 2012) shows that some school administrators have very low confidence in the effectiveness of the interview selection processes used in their jurisdiction, especially as they often hire new teachers for system positions rather than for their own schools. Second, new teachers may be unaware of how to prepare for hiring, how interviews are conducted, and how to anticipate the needs of various jurisdictions, thereby leaving them unaware of how to improve their prospects of having a good interview and obtaining their first teaching position.

Interviewing prospective teachers, especially when hiring administrators are untrained for the hiring task, is largely a subjective process, as evidenced in Cranston's (2012) study. This subjectivity is at odds with the objective goal of hiring the teacher(s) with the most potential to impact student achievement. The tension between the use of objective criteria for hiring (Harris, Rutledge, Ingle, \& Thompson, 2007) and the subjective practice of hiring based on interviews and references may confuse the issue of trying to ensure that the most effective teachers ultimately get hired. This tension defines the key weakness of our current practice of relying too heavily, even exclusively, on interviews to select the most promising new teachers. When the subjective approach of relying on interviews is used exclusively, the high stakes task of hiring the most effective teachers may rely on a faulty assumption; that those responsible for hiring can successfully identify the candidates' characteristics through the interview process alone (Kristof-Brown, Zimmerman, \& Johnson, 2005).

\section{School-based hiring}

School-based hiring may provide those charged with the task of hiring teachers with better teachers (Darling-Hammond, 1997; DeArmond, Gross, \& Goldhaber, 2010). This may be because the people responsible for hiring at the school level have more commonly held views of fit, whether these are acknowledged or unacknowledged, and therefore examine the suitability of the applicants more thoroughly to ensure a suitable fit. Therefore, school-based 
hiring may ensure more confidence among hiring team members than hiring that is undertaken to fill system-wide needs. By implementing school-based hiring, principals can select new teachers whose characteristics they perceive to be the best fit for the school and its needs (Deal \& Peterson, 1999; Firestone \& Louis, 1999). This practice supports the healthy development of the desired school culture. However, in many jurisdictions, administrators hire for system positions and may have little say in who is assigned to their school.

In system-wide hiring the hiring team members get little or no opportunity, as a new teacher's career progresses, to verify the strength of their decisions about whom they have hired (Maynes \& Hatt, 2013). This dilemma identifies the need to ensure that hiring jurisdictions use an approach that is comprehensive and consistent for the task of hiring new teachers (Fullan, 2011).

\section{Predictive hiring}

Some jurisdictions are now using a multi-staged selection process, called predictive hiring, that attempts to find the best fit among teacher candidates using techniques that supplement the traditional interview (Pappano, 2011). Such multi-stage hiring processes address the need to support educational improvement by attempting to predict the best teachers to hire after acquiring several data sets on each applicant. This helps those who are hiring to flag problematic fits at an early stage in the process. Multi-stage hiring processes support the traditional resume, application letter, and interview with the addition of further filters. Additional filters provide better data upon which to make a teacher hiring decision. The best applicant for the teaching position will fit in several ways, including a fit between the applicant and the work environment, the job requirements, the organization/school and its culture, and the group with whom they will be working (Anderson, Lievens, van Dam \& Ryan, 2004; Antonioni \& Park, 2001; Ehrhart\&Makransky, 2007; Kristof-Brown et al, 2005; Sekiguchi, 2004). Since a prior study has shown that assessments of fit between the applicant and the organizational culture predominate in hiring decisions (Karren\& Graves, 1994), a multi-stage approach provides opportunities for better informed decisions about the applicant's fit for the position.

However, while these measures of fit may be varied and may provide some diverse data in the hiring process, it seems unlikely that interviewers are simultaneously and systematically assessing fit as the compatibility between the interviewee and the professional demands of teaching, competence for the job, organizational fit, and group fit in the absence of a conceptual framework to structure these diverse and sometimes competing goals.

\section{Using other evidence to support interview data when hiring}

Cranston's (2012) research suggests that various forms of evidence offered by new teachers in the current hiring processes in many jurisdictions is undervalued or dismissed outright.He found three themes that were evident in hiring practices. First, there was variance across the province (in mid-western Canada) in the centralization of the hiring process, ranging from nearly exclusively centralized, to almost completely school based. Although the majority $(61 \%)$ of interviews were conducted at the school level, the final decision of who to hire was 
generally a joint endeavor of the central office and school personnel. Second, he found that personal characteristics as demonstrated in interviews and previous experience supported by references were the most important factors in determining whom to hire. Resumes were valued as third most important, while practica reports, which showed the teacher's ability within the classroom, were less valued. Lastly, he found that measures of academic proficiency, such as teacher portfolios, grade-point-average, and the reputation of the accrediting university, were generally undervalued.

Mason and Schroeder (2010) surveyed 60 randomly selected K-12 principals in Wisconsin to determine who was involved in the hiring process and what principals looked for in candidates. They found principals were almost always involved in interviews with applicants, and grade or subject teachers were involved half the time, while superintendents were only involved $13 \%$ of the time. This demonstrated that a "decentralized team-based approach" ( $p$. 190) was most common.

The study also revealed positive and negative characteristics that principals look for during interviews. They found that positive attributes tended to consist of personal traits, such as excitement, appearance, confidence, and attitudes. Negative attributes were generally deficits of the positive attributes. While personal attributes were considered during the interview process, which held the most significance in hiring decisions, professional attributes (letters of reference, resume, experience, grade point average) held more weight during the initial review and screening of applicants.

Finally, Mason and Schroeder (2010) found that principals gave the most value to verbal references and first impressions, and the least value to portfolios (paper and electronic) when determining who to hire. Therefore, greater weight is given to "richer assessments of teacher quality" (p. 191) such as recommendations from persons who have observed the applicant as s/he taught.

\section{Assessing the evidence for hiring good teachers}

Clearly complicating the teacher selection process is the lack of clarity about what evidence points out most favourably the characteristics of an effective teacher. That is, while we may know that we want to hire teachers who will consistently focus their professional efforts on ensuring students' learning, we may have little understanding of how to uncover these characteristics using traditional interview techniques. Some studies show that portfolios are less valued than other offerings or evidence provided by teacher applicants, while other studies point to the value and use of portfolios and e-portfolios as an aspect of the selection process, to help hiring teams determine evidence of teacher effectiveness.

Strawhecker, Messersmith, and Balcom (2008) used a survey to conduct a mixed-method study on the use of e-portfolios by K-12 teacher applicants. They discussed principals' perspectives of the benefits and disadvantages of examining a candidate's portfolio as part of their interview, and principals' preferred content and delivery method. It was noted that e-portfolios were a popular method, promoted by teacher training institutions, of 
demonstrating applicant's accomplishments and multi-modal technological capabilities in an accessible way.

When looking at the perspectives of hiring officials, Strawhecker et al. (2008) found that e-portfolios were viewed positively by hiring principals, as they provided an opportunity to view actual artifacts and provided a convenient and comprehensive look at the applicant and her/his demonstrated organization skills. However, many limitations were also noted, including having limited time to view the e-portfolio, especially if it included a great deal of information. Hiring officials suggested that an interview was not an appropriate time for viewing an e-portfolio and noted that poorly prepared portfolios reflected negatively on applicants. Finally, many hiring officials stated they had difficulty evaluating the variety of portfolios and would have preferred a standardized format.

Furthermore, reflecting similar findings by Cranston (2012), Strawhecker at al. found that principals wanted most to see the candidate's resume, references, letters of recommendation, transcripts, and student teacher evaluations. Finally, they found that principals who had previously accepted e-portfolios and who had been in the principal position longest were more receptive to receiving them in the future.

Strawhecker et al (2008) and Sivakumaran, Holland, and Heyning (2010) noted the popularity and advantages of e-portfolios. They surveyed over 500 participants, including superintendents, principals, and human resource administrators from Wisconsin and Louisiana to determine the level of acceptance of e-portfolios and preferred content. Although the vast majority of participants noted that portfolios were not required, most were willing to review them if supplied, although this did not increase the applicant's likelihood of being hired. Over half of the participants, however, stated that they preferred paper-based portfolios.

They found that the preferred content included resumes, recommendations, lesson plans, and work experience. In addition, hiring agents were more likely to accept digital portfolios if they considered themselves tech savvy. In conclusion, they recommended that applicants continue to use this form of presentation to support their employment applications, as greater use would increase hiring agent's comfort with accepting e-portfolios as evidence of their professional capabilities.

Similar results about the use of evidence from portfolios to support interviews and hiring practices were found in a study conducted by Nodoye, Ritzhaupt, and Parker (2012). They surveyed 49 principals to determine the pro and cons of e-portfolios, the content or desired items, when they should be submitted, and the preferred method of delivery. Participants in the study indicated that e-portfolios were beneficial as they provided detailed information about the candidate, were easily accessible and organized, and demonstrated an applicants' effort and ability. Some negatives, however, were that they were time consuming to view and evaluate, lacked standardization, and only showed the applicants' best work.

Nodoye, Ritzhaupt, and Parker (2012) found the most desired artifacts to be resumes, references, letters of recommendation, and reflections on teaching experience. Principals also 
preferred to use e-portfolios as part of the interview process or during initial screening of candidates, and preferred a website URL. They found that principals who had previously used e-portfolios were more willing to use them again. Finally, they found that principals desired a standardized format be used with a provided rubric for evaluating an applicant's portfolio, and that technology training should be provided for the hiring teams so that they could make the best use of e-portfolios in the selection process. They concluded that teacher-training institutions should place less emphasis on the creation of e-portfolios and should collaborate with hiring agencies to understand the teacher applicant evaluation process better.

The use of portfolios is unequally valued which further complicates the fairness or common practices for teacher selection. Theories about optimizing human capital (Schultz, 1961) to get the best fit of candidate to needs may be more subjective than productive, and predictive approaches to hiring, such as the systematic assessment of evidence documents such as portfolios, while showing some promise of positive yields, are yet to be proven and are labour intensive to implement.

\section{Using a multi-stage hiring process}

Experienced educational supervisors recognize that supporting, supervising, and possibly terminating ineffective teachers is much more costly to all involved than is the cost of a multi-staged interview process. This reality alone is reason enough to continue to examine the approaches currently being used to hire and support new teachers. The remainder of this paper will explore research that demonstrates administrators' levels of confidence in interviews, training we might provide for teacher applicants to engage effectively in interviews, and supplementary practices that may be implemented to support the traditional use of interviews as the most influential practice in our teacher-hiring repertoire.

\section{Methodology}

\section{Participants}

Twenty-three school administrators from two northern school districts responded to an online survey. One group of respondents (15)was employed by a Catholic district school board, while the other participants (8) were administrators in a public district school board. One of the 23 respondents was a vice-principal while the remaining 22 were school principals.

Among the respondents there were 18 elementary school administrators and 5 secondary school administrators. Thirteen of the participants were female; 10 were male. The participants had an average of 21 years of teaching experience, and a range of 1 to 16 years of administrative experience.

\section{Methods}

Mixed methods were used to collect data in an online survey of school administrators in two northern Ontario school districts. The questionnaire was divided into two parts. The first part provided demographic data about the participants and involved 10 questions. The second part of the survey involved 41 questions in three sets. Within each set of questions there were 
three foci: 1) to determine the respondents' perception of the value they placed on an identified teacher characteristic; 2) to identify info-data respondents could gather from interview situations that provided assurance that the teacher candidate evidenced the characteristic; and 3) ideas about strategies each participant would use to support growth in the characteristic after they had hired the teacher.

The first part of each set of questions was collected on a 5-point Likert scale. The second and third parts of each question set were collected using qualitative responses to a prompt, for example; "If a pre-service teacher is developing the ability to use caring classroom management techniques, what professional characteristics will be evident to you during an interview for hiring?" and "What do you do in your role as an administrator to support novice teachers in developing their ability to use caring classroom management techniques?"

\section{Data}

The 51 question survey was distributed to school administrators through online sites accessed through the Director of each school board. Directors explained the research to administrators and how to access the survey through an internal system letter. The survey required completion of a letter of informed consent and the questions took approximately 60 to 80 minutes to complete. Participants could exit and re-enter the survey to complete it in more than one sitting.

Both qualitative and quantitative data were collected from the survey data and sorted into sets of three related responses. These sets included questions about: 1) the extent to which the administrator valued the teacher characteristic; 2) the ways in which the administrator searched for evidence of that characteristic in teacher interviews; and 3) the strategies used by the administrator to support new teachers' development of the valued characteristic once they were hired. In each data set, the first question yielded quantitative data while the remaining two parts of each set provided qualitative data. The quantitative data were analyzed by percentages while the qualitative data were analyzed for recurring themes (Creswell, 2012).

\section{Results}

Results of the quantitative aspects of this study are as follows. On the survey, 17 characteristics were proposed as those which might describe effective classroom teachers. Administrators were asked to identify each characteristic as "very important"(5), "important", "neutral" (3), "unimportant"(2) or "very unimportant"(1) in the teachers they hired. Characteristics described as being important were divided into three groups that reflect, by percentage, the importance attached to each characteristic by the administrators.

First, administrators felt very strongly ( $79 \%$ and above) that the following characteristics were among those they would look for in new teachers: skill with different uses of assessment; caring classroom management techniques; a rich instructional repertoire; pedagogical content knowledge; and, the ability to plan, implement and assess learning.

Second, administrators felt moderately strongly (between 58 and 68\%) that the following characteristics were among those they would look for in new teachers: the ability to act 
professionally and personally in accordance with the principles of social justice and equity; learner focused instructional efforts; willingness to extend their professional learning once they were hired; having a professional presence while teaching; and, having effective management and communication practices.

Finally, administrators felt least strongly (between 50 and 22\%) that the following characteristics were among those they would look for in new teachers: a professional growth orientation; having values that reflected the curriculum goals of the local curriculum guidelines; being able to read the body language of the learner; being able to reflect on and articulate their professional practice; showing passion and enthusiasm; and, supporting students' awareness of global issues and contexts.

It must be noted that while there were distinct differences in the number of participants who identified some of the 17 characteristics as very important, when the categories of "important" and "very important" were considered together, there was surprisingly strong support (69 to $100 \%$ ) for all of the characteristics of new teachers that were questioned in the survey, with the exception of passion and enthusiasm, which were identified as important or very important by only $54 \%$ of the participants (see Table 1 ).

Table 1. Participants' Valuing of Various New Teacher Traits

\begin{tabular}{|c|c|c|c|c|c|}
\hline & \multirow{2}{*}{$\begin{array}{l}\text { Very } \\
\text { Important }\end{array}$} & \multirow[t]{2}{*}{ Important } & \multirow[t]{2}{*}{ Neutral } & \multicolumn{2}{|c|}{ I Unimportant Very } \\
\hline & & & & & Unimportant \\
\hline Different Uses of Assessment & $90 \%$ & $5 \%$ & $5 \%$ & $0 \%$ & $0 \%$ \\
\hline Caring Classroom Management Techniques & $86 \%$ & $14 \%$ & $0 \%$ & $0 \%$ & $0 \%$ \\
\hline Rich Instructional Repertoire of Strategies & $86 \%$ & $14 \%$ & $0 \%$ & $0 \%$ & $0 \%$ \\
\hline Pedagogical Content Knowledge & $80 \%$ & $20 \%$ & $0 \%$ & $0 \%$ & $0 \%$ \\
\hline Plan, Implement and Assess Learning & $79 \%$ & $21 \%$ & $0 \%$ & $0 \%$ & $0 \%$ \\
\hline Act Professionally and Personally in Accordance with Principles of & $68 \%$ & $26 \%$ & $5 \%$ & $0 \%$ & $0 \%$ \\
\hline Social Justice and Equity & & & & & \\
\hline Learner Focused Instructional Efforts & $68 \%$ & $32 \%$ & $0 \%$ & $0 \%$ & $0 \%$ \\
\hline Passion and Enthusiasm for Content & $68 \%$ & $27 \%$ & $5 \%$ & $0 \%$ & $5 \%$ \\
\hline Extend Professional Learning & $65 \%$ & $20 \%$ & $10 \%$ & $0 \%$ & $5 \%$ \\
\hline Develop Professional Confidence & $62 \%$ & $24 \%$ & $10 \%$ & $5 \%$ & $0 \%$ \\
\hline Professional Presence While Teaching & $62 \%$ & $33 \%$ & $5 \%$ & $5 \%$ & $0 \%$ \\
\hline Management and Communication Practices & $58 \%$ & $37 \%$ & $5 \%$ & $0 \%$ & $0 \%$ \\
\hline Professional Growth Orientation & $50 \%$ & $32 \%$ & $18 \%$ & $0 \%$ & $0 \%$ \\
\hline Values Reflect Curriculum Goals in Local Guidelines & $47 \%$ & $42 \%$ & $11 \%$ & $0 \%$ & $0 \%$ \\
\hline Read Body Language of Learners & $45 \%$ & $36 \%$ & $14 \%$ & $0 \%$ & $5 \%$ \\
\hline Reflectively Articulate Professional Practice & $37 \%$ & $32 \%$ & $26 \%$ & $5 \%$ & $0 \%$ \\
\hline Instruction to Support Students Awareness of Global Issues and 2 & $22 \%$ & $50 \%$ & $22 \%$ & $6 \%$ & $0 \%$ \\
\hline Contexts & & & & & \\
\hline
\end{tabular}




\section{Correlations in the Data}

Both cross-tabulations and correlations across the data were analyzed to help us discover trends. Participants were asked to identify the number of times they had engaged in hiring and the number of times they were dissatisfied with the results of their choices. The following results were identified:

- the average (mean) number of times that participants had participated in hiring new teachers was 24 times, with an average satisfaction with their decision of 23 times out of 24;

- the average dissatisfaction rate among participants was 4 persons, with dissatisfaction rates being comparable for both male and female administrators;

- on average, male administrators had participated in hiring 10 more teachers than female administrators;

- male administrators report a higher satisfaction with their hiring choices than do female administrators, which may reflect their increased experience with the role; and,

- $\quad$ secondary school administrators participated in more hiring than elementary school administrators, and showed a correspondingly higher rate of satisfaction with their choices.

In examining correlations across demographic data among this group of participants, the following trends were identified:

- there was a weak correlation (0.183) between the number of years as an administrator and the respondent's perception of how satisfied they were with their hiring choices. This was unexpected as one might think that more experience on the job would help an administrator identify better criteria to apply to new teacher hiring;

- there was strong positive correlation (0.948) between the number of persons an administrator had been involved in hiring and the rate of satisfaction they expressed with their decisions, showing that increased experience with selecting and hiring new teachers relates to how many teachers an administrator is satisfied with once the new teacher starts the job; and

- there was a moderate correlation (0.313) between the length of time an administrator had held their current position and their satisfaction with the teachers they had participated in hiring, suggesting that the longer a person holds the same administrative position, the better able they are to identify and find the qualities in applicants that they believe make a good teacher.

\section{Discussion}

Initial analysis of data from this research (Maynes \& Hatt, 2013) was completed to examine administrators' beliefs about the importance of the 17 teacher characteristics that were presented in this survey and to validate a model, which we called Professional Shift Theory (pst). We therefore recognize that the set of teacher characteristics that were offered to respondents in this research is a limited set and that there may be many more and many 
different characteristics, which administrators may desire when they hire new teachers. We suggest that the real value of this analysis is in the exercise itself. That is, we believe that it is vitally important for administrators who have a role in teacher hiring to go through a process of identifying the characteristics that they think are important in those whom they hire. This seems to be uncommon. Rather, it seems increasingly likely that administrators are hiring for system roles rather than for school based positions and increasingly likely that they have little, if any, role in the pre-selection criteria to determine who is interviewed and in the questions that are used during interviews. This separation of roles, although likely intended to provide fairness for applicants and save time for administrators, is a misplaced effort. Administrators need to engage in the examination of applicants' suitability for teaching positions through all phrases of the application and interview process.

As a direct result of this research and our findings that suggested that some administrators lack confidence in the interview as a vehicle to help them identify the strongest teachers, two further resources have been developed. The first is a book intended for teacher applicants. This book, called Ten Things You Need to Know Before You Interview for aTeaching Job (Maynes \& Sharpe, 2013) explains in detail the application and interview process that is currently used by many school jurisdictions. It was designed to help teacher applicants visualize the interview process and deal with developing professional answers to interview questions. The second book, entitled When the Interview is not Enough: A Multi-Stage High Impact Process for Hiring New Teachers (Maynes \& Hatt 2014), is intended for use by school and system administrators. This book suggests that our current process of hiring new teachers based on a written application, resume, and a brief interview is not rigorous enough to be an effective way to ensure that we hire teachers with the most promising potential to have a positive impact on students' learning. The book suggests an alternative 9-step process that could be used and provides an outline of the administrator training that would be needed to use this more intense process for teacher hiring. It is our belief that the dissemination of these two resources will help to profile the issue of teacher hiring and to start discussions about the processes we currently use and their efficacy in a Canadian context.

\section{Limitations}

The study reported in this paper, involved analysis of data from a survey of 23 school administrators in 2 school jurisdictions. Replication of this study with a wider group of participants would strengthen the data set and provide broader perspective on the issues that were our focus. It would be especially valuable to ensure a larger set of secondary school administrator responses as this research suggests that secondary administrators may have more confidence in the validity of brief interviews to select effective teachers than is commonly perceived by elementary school administrators. A larger sample from both groups would allow us to examine this trend more thoroughly.

\section{Implications for Further Research}

Further research in the area of teacher hiring, novice teacher supports, and new teacher retention is needed in the Canadian context. While there are pockets of research beginning in this area of study in Canada, the vast majority of the research that we were able to find is 
being done in the United States. Our earlier research (Maynes \& Hatt, 2013) also showed that school administrators lack a clear understanding of the elements of professional support that are required to engage professionals in an effective mentorship/coaching relationship. The current research being done by others into the effectiveness of early career mentoring in our jurisdiction clearly demonstrates the inequities across various school boards in design, access, topics, and supports that are available for new teachers. While further work in this area of research is needed, and further preparation for school administrators is indicated by current research, our most immediate interest is in developing a more rigorous method of hiring teachers so that the best teachers have opportunities to teach.

\section{References}

Anderson, N., Lievens, F., van Dam, K., \& Ryan, A. (2004). Future perspectives on employee selection: Key directions for future research and practice. Applied Psychology: An International Review, 53, 487-501. http://dx.doi.org/10.1111/j.1464-0597.2004.00183.x

Antonioni, D., \& Park, H. (2001). The effect of personality on peer ratings of contextual workbehaviours. Personnel Psychology, 331-360. http://dx.doi.org/10.1111/j.1744-6570.2001.tb00095.x

Bieler, D. (2012). What new teachers want from colleagues.Educational Leadership, 69(8), 46-49.

Bill and Melinda Gates Foundation. (2010). Learning about teaching: Initial findings from the Measures of Effective Teaching Project. Retrieved from: www.gatesfoundation.org/.../preliminary-findings-research-paper.pdf

Boyd, D., Goldhaber, D. D., Lankford, H. \& Wyckoff, J. H. (2007). The effect of certification and preparation on teacher quality. The Future of Children, 17, 45-68. http://dx.doi.org/10.1353/foc.2007.0000

Brock, B. L. \& Chatlain, G. (2008). The status of teacher induction in Catholic schools: Perspectives from the United States and Canada. Catholic Education: A Journal of Inquiry and Practice, 11(3), 370-384.

Campbell R. J., Kyriakides, L., Muijs, R. D., \& Robinson, W. (2003). Differential teacher effectiveness: Towards a model of research and teacher appraisal. Oxford Review of Education, 29, 347-362. http://dx.doi.org/10.1080/03054980307440

Cashin, W. E. (1994). Student ratings of teaching: A summary of the research. In K. A. Feldman and M. B. Paulsen (Eds.), Teaching and learning in the college classroom (pp. 531-541). Needham Heights, MA: Simon and Schuster.

Cherubini, L. (2009). New teachers' perceptions of induction: Insights into principled practice. Alberta Journal of Educational Research, 55(2), 185-198.

Clark, S. K., \& Byrnes, D. (2012). Through the eyes of the novice teacher: Perceptions of mentoring support. Teacher Development, 16(1), 43-54. http://dx.doi.org/10.1080/13664530.2012.666935 


\section{Macrothink}

Journal of Studies in Education

ISSN 2162-6952

2015, Vol. 5, No. 2

Cochran-Smith, M., \& Power, C. (2010). New directions for teacher preparation.Educational Leadership, 67(8), 6-13.

Cranston, J. A. (2012). Evaluating prospects: The criteria used to hire new teachers. Alberta Journal of Education Research, 58(3), 350-367.

Creswell, J.W. (2012). Qualitative inquiry and research design. (3 ${ }^{\text {rd }}$ ed.). Thousand Oaks, CA.: Sage.

Darling-Hammond, L. (1997). Doing what matters most: Investigations in quality teaching. New York: National Commission on Teaching and America's Future, Teachers College, Columbia University.

Darling-Hammond, L. (2001). The challenge of staffing our schools. Educational Leadership, 58(8), 12-17.

Darling-Hammond, L. (2003). Keeping good teachers: Why it matters, what teachers can do. Educational Leadership, 60(8), 6-13.

Darling-Hammond, L., \& Berry, B. (1999). Recruiting teachers for the $21^{\text {st }}$ century: The foundation for educational equity. Journal of Negro Education, 68, 254-279. http://dx.doi.org/10.2307/2668100

Deal, T. E., \& Peterson, K. D. (1999).Shaping school culture: The heart of leadership: San Francisco: Jossey-Bass.

DeArmond, M., Gross, B., \&Goldhaber, D. (2010). Is it better to be good or lucky? Decentralized teacher selection in 10 elementary schools. Educational Administration Quarterly, 46, 322-362. http://dx.doi.org/10.2307/2668100

Dinham, S., Ingvarson, L., \& Kleinhenz, E. (2008). Teaching talent: The best teachers for Australia's classrooms. Teaching standards and teacher evaluation. Retrieved from:http://research.acer.edu.au/teaching_standards. 12

Ehrhart, K. H. \&Makransky, G. (2007). Testing vocational interests and personality as predictors of person-vocation and person-job fit. Journal of Career Assessment, 15, 206-226. http://dx.doi.org/10.1177/1069072706298105

Firestone, W. A., \& Louis, K. S. (1999). Schools as cultures. In J. Murphy \& K. S. Louis (Eds.), Handbook of research on educational administration ( $2^{\text {nd }}$ ed., pp.297-322). San Francisco: Jossey-Bass.

Fullan, M. (2011). Choosing the wrong drivers for whole system reform (Seminar Series paper No. 204). East Melbourne, AU: Centre for Strategic Education. Retrieved from: www.cse.edu.au.

Glassford, L. A., \& Salinitri, G. (2007). Designing a successful new teacher induction program: An assessment of the Ontario experience, 2003-2006. Canadian Journal Of Educational Administration And Policy, (60), 1-34. 
Gladwell, M. (2008, December 15). Most likely to succeed.The New Yorker. Retrieved from:www.newyorker.com/reporting/2008/12/15121fa_fact_gladwell.

Goldhaber, D., \& Hansen, M. (2010). Using performance on the job to inform teacher tenure decisions. American Econonic Review: Papers and Proceedings, 100, 250-255. Retrieved from:www.aea.org/articles.php?doi=10.1257/aer.100.2.250.

Harris, D. N. (2004). Putting a high-quality teacher in every Florida classroom: Policy brief. Retrieved from:www.nepc.colorado.edu/files/EPSL_0404-111-EPRU.pdf.

Harris, D. N., Rutledge, S. A., Ingle, W. K., \& Thompson, C. C. (2007). Mix and match:

What principals look for when hiring teachers and what it means for teacher quality policies. Retrieved from:www.teacherqualityresearch.org/mix_match.pdf.

Hentges, J. (2012). Why do beginning teachers leave the profession? What can be doneabout it? Global Education Journal, (3), 100-105.

Herriot, P. (1989). Recruitment in the 1990s. London: Institute of Personnel Management.

Ingersoll, R., Merrill, L., \& May, H. (2012). Retaining teachers: How preparation matters. Educational Leadership, 69(8), 30-34.

Jacob, B., \&Lefgren, L. (2006). When principals rate teachers. Education Next, 6(2), 59-64. Retrieved from:www.Educationnext.org/journal/spring06/.

Karren, R. J., \& Graves, L. M. (1994). Assessing person-organization fit in personnel selection: Guidelines for future research. International Journal of selection and Assessment, 2, 146-156. http://dx.doi.org/10.1111/j.1468-2389.1994.tb00135.x

Kelley, L. (2004). Why induction matters. Journal Of Teacher Education, 55(5), 438-448. http://dx.doi.org/10.1177/0022487104269653

Kristof-Brown, A. L., Zimmerman, R. D., \& Johnson, E. C. (2005). Consequences of individuals' fit at work: A meta-analysis of person-job, person-organization, person-groups and person-supervisor fit. Personal Psychology, 58, 281-342. http://dx.doi.org/10.1111/j.1744-6570.2005.00672.x

Lambeth, D. (2012). Effective practices and resources for support of beginning teachers. Academic Leadership Journal, 10(1), 1-13.

Little, O., Goe, L., \& Bell, C. (2009).A practical guide to evaluating teacher effectiveness. Washington, DC: National Comprehensive Center for Teacher Quality. Retrieved from:www.tqsource.oeg/publications/practicalGuide.pdf.

Martin, E. P., Andrews, S. P., \& Gilbert, L. S. (2009). New teachers and support: An examination of ratings of significant agents. Research In The Schools, 16(1), 25-31.

Mason, R. W., \& Schroeder, M. P. (2010). Principal hiring practices: Toward a reduction of uncertainty. Clearing House, 83(5), 186-193. http://dx.doi.org/10.1080/00098650903583727 
Maynes, N. \& Hatt, B.E. (2014). When the interview is not enough: A multi-stage high impact process for hiring new teachers. Germany: Lambert Academic Publishing.

Maynes, N. \& Sharpe, G. (2013). Ten things you need to know before you interview for a teaching job. Indiana: Xlibris Publishers.

Maynes, N., \& Hatt, B. (2013).Hiring and supporting new teachers who focus on students' learning. Canadian Journal of Educational Administration and Policy. \#144, 1-37.

Maynes, N. and Hatt, B.E., (2012). Shifting the Focus to Student Learning: Characteristics of Effective Teaching Practice As Identified by Experienced Pre-service Faculty Advisors, Brock Journal 22 (1), 93-110.

Montgomery, C. (1996). Organization fit is key to job success. HR Magazine, 41(1), 94-97.

Nodoye, A., Ritzhaupt, A., \& Parker, M. A. (2012). Use of eportfolios In K-12 teacher hiring in North Carolina: Perspectives of school principals. International Journal Of Education Policy \& Leadership, 7(1-5), 1-10.

Organization for Economic Cooperation and Development (OECD).(2004, February). The quality of the teaching workforce: Policy brief. OECD Observer. Retrieved from:www.oecd.org/dataoecd/17/9/29478720.pdf.

Organization for Economic Cooperation and Development (OECD). (2005). Teachers matter: Attracting, developing and retaining effective teachers. Paris: OECD.

Organization for Economic Cooperation and Development (OECD). (2012). What can be done to support new teachers? Education Journal, (141),8.

Pappano, L. (2011). Using research to predict great teachers. Harvard Education Letter, 27(3).

Plumbley, P. (1985). Recruitment and selection, (4 ${ }^{\text {th }}$ ed.). London: Institute of Personnel Management.

Rabowinski, W., \& Travers, R. M. W. (1953). Problems of defining and assessing teacher effectiveness. Educational Theory, 212-219. http://dx.doi.org/10.1111/j.1741-5446.1953.tb01052.x

Rivkin, S. J., Hanushek,E. A., \&Kain, J. F. (2005). Teachers, schools, and academic $\begin{array}{lll}\text { achievement. } & \text { Econometrica, 717-458. }\end{array}$ http://dx.doi.org/10.1111/j.1468-0262.2005.00584.x

Schultz, T. W. (1961). Investment in human capital.American Economic Review, 51, 1-16.

Sekiguchi, T. (2004). Person-organization fit and person-job fit in employee selection: A review of the literature. Osaka KeidaiRonshu, 54(6), 179-196.

Sivakumaran, T., Holland, G., \&Heyning, K. (2010). Hiring agents' expectations for new teacher portfolios. National Forum Of Teacher Education Journal, 20(3), 1-6. 


\section{Macrothink}

Journal of Studies in Education

ISSN 2162-6952 2015, Vol. 5, No. 2

Strawhecker, J., Messersmith, K., \& Balcom, A. (2008). The role of electronic portfolios in the hiring of K-12 teachers. Journal Of Computing In Teacher Education, 24(2), 65-71.

Tait, M. (2005). Resilience and new teacher success. Education Today, 17(3), 12-13.

Teague, D., Swan, J. (2013). Enhancing the future of education by actively supporting novice teachers. Delta Kappa Gamma Bulletin, 80(1), 41-52.

Vessey, I. The theory of cognitive fit: One aspect of a general theory of problem solving? in P. Zhang and D. Galletta (eds.), Human-computer interaction and management information systems: Foundations, Advances in Management Information Systems Series, Armonk, NY: M.E. Sharpe, 2006.

Walsh, K., \& Tracy, C. O. (2004). Increasing the odds: How good policies can yield better teachers. Washington, DC: National Council on Teacher Quality.

Wise, A. E., Darling-Hammond, L., \& Berry, B. (1987). Effective teacher selection: From recruitment to retention. CA: Santa Monica, RAND.

Young, J., Levin, B., \& Wallin, D. W. (2007). Understanding Canadian schools: An introduction to educational administration $\left(4^{\text {th }}\right.$ ed.). Toronto: Nelson.

Zhu, C. J., \& Dowling, P. J. (2002). Staffing practices in transition: Some empirical evidence from China. International Journal of Human Resource Management, 13, 569-597. http://dx.doi.org/10.1080/09585190110092776 